\title{
MODELING OF ELECTROMAGNETIC FORCE WITH A MAGNETIC VECTOR POTENTIAL FORMULATION VIA A SUBPROBLEM FINITE ELEMENT METHOD
}

\author{
Dang Quoc Vuong \\ School of Electrical Engineering - Hanoi University of Science and Technology
}

\section{ABSTRACT}

The aim of this study is based on a subproblem finite element method with a magnetic vector potential formulation to anaylize electromagnetic forces due to the distribution of leakge magnetic flux densities in air gaps and electric current denisities in coils that are somewhat difficult to apply directly a finite element method as some studied conducting regions are very small in comparison with overall of the whole studied domain. The method is herein presented for coupling problems in several steps: A problem invloved with simplified models (stranded inductors) is first solved. The next problem consisting of one or two conductive regions can be added to improve errors from previous subproblems. All the steps are independently solve with different meshes and geometries, which facilitates meshing and reduces calculation time for each subproblem.

Keywords: Electromagnetic force; leakage magnetic flux density; finite element method; magnetodynamics; subproblem finite element method; magnetic vector potential formulation.

Received: 13/02/2020; Revised: 27/02/2020; Published: 28/02/2020

\section{MÔ HÌNH HOÁ CỦA LỬC ĐIÊN TỪ VớI CÔNG THỨC TỪ THẾ VÉC TƠ BẦNG PHƯỚNG PHÁP BÀI TOÁN NHỎ}

\author{
Đặng Quốc Vương \\ Viện Điện - Truờng Đại học Bách khoa Hà Nội
}

\section{TÓM TẮT}

Mục đích của nghiên cứu này được dựa trên phương pháp miền nhỏ hữu hạn với công thức véc tơ từ thế để phân tích lực điện từ tạo ra bởi sự phân bố của mật độ từ cảm tản trong khe hở không khí và mật độ dòng điện trong các cuộn dây, cái mà khó có thể thực hiện trực tiếp bằng phương pháp phần tử hữu hạn, khi mà một số vùng dẫn nghiên cứu có kích thước rất nhỏ so với toàn bộ miền nghiên cứu. Phương pháp bài toán nhỏ được áp dụng ở đây để liên kết các bài toán theo một vài bước: Một bài toán với mô hình đơn giản (các cuộn dây) được giải trước. Bài toán tiếp theo bao gồm một hoặc nhiều miền dẫn từ được đưa vào để hiệu chỉnh sai số do bài toán trước đó gây ra. Tất cả các bước đều được giải độc lập trong lưới và miền hình học khác nhau, điều này tạo thuận lợi cho việc chia lưới cũng như tăng tốc độ tính toán của mỗi một bài toán nhỏ.

Từ khóa: Lực điện tù;; mật độ tù cảm tản; phuơng pháp phần tử hũu hạn; bài toán tù̀ động; phương pháp miền nhỏ hũu hạn; công thức tù̀ thế véc to:

Ngày nhận bài: 13/02/2020; Ngày hoàn thiện: 27/02/2020; Ngày đăng: 28/02/2020

Email:vuong.dangquoc@hust.edu.vn

\section{https://doi.org/10.34238/tnu-jst.2020.02.2620}




\section{Introduction}

Many authors in [1-2] have been recently proposed a subproblem approach for improving accuracies of fields such as eddy current losses, power losses and magnetic fields in the vicinity of thin shell models in stead of using directly a finite element method [3-6], that usually gets some troubles when the dimension of the computed conducting domains is very small in comparison with the whole problem. In this study, the subproblem method (SPM) is extended for computing electromagnetic forces (EMFs) due to the distribution of leakge flux magnetic fields in air gaps and electric currents in coils electrocoupling subprolems (SPs) in several steps (Fig. 1):

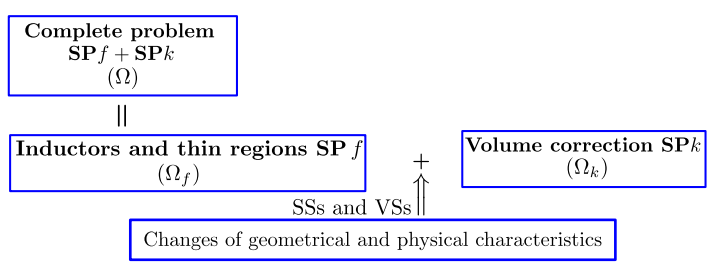

Figure 1. Division of a complete problem into two subproblems

A problem invloved with simplified models (stranded inductors or stranded inductors and conductive thin regions) is first solved. The next problem with volume correction consisting of one or two conductive regions can be added to improve errors from previous subproblems.

Each SP is contrained via volume sources (VSs) or surface sources (SSs), where VSs are change of permeability and conductivity material of conduting regions, and SSs are the change of interface conditions (ICs) or boundary conditions (BCs) through surfaces from SPs.

The scenario of this method permits to make use of solutions from previous computations instead of starting again a new complete problem for any variation of geometrical or physical characteristics. Therefore, each SP is solved on its own domain and mesh without depending on the previous meshes and domains. The method is highlighted and validated on a test practical problem.

2. Subproblem method for magnetodynamic problem

\subsection{Canonical magnetodynamic problem}

As proposed in [1-2], a canonical magnetodynamic problem $i$, to be solved at step $i$ of the SPM, is defined in a $\Omega_{i}$, with boundary $\partial \Omega_{i}=\Gamma_{h, i} \cup \Gamma_{e, i}$. Subscript $i$ refers to the associated problem $i$. Based on the set of Maxwell's equations [3-6], the equations, material relations, BCs of SPs are written as

$$
\begin{array}{r}
\operatorname{curl} \boldsymbol{h}_{i}=\boldsymbol{j}_{i}, \operatorname{div} \boldsymbol{b}_{i}=0, \operatorname{curl} \boldsymbol{e}_{i}=-\boldsymbol{\partial}_{t} \boldsymbol{b}_{i} \\
(1 \mathrm{a}-\mathrm{b}-\mathrm{c}) \\
\boldsymbol{h}_{i}=\mu_{i}^{-1} \boldsymbol{b}_{i}+\boldsymbol{h}_{s, i}, \boldsymbol{j}_{i}=\sigma_{i} \boldsymbol{e}_{i}+\boldsymbol{j}_{s, i}(2 \mathrm{a}-\mathrm{b}) \\
\boldsymbol{n} \times\left.\boldsymbol{h}_{i}\right|_{\Gamma_{h, i}}=0,\left.\quad \boldsymbol{n} \cdot \boldsymbol{b}_{i}\right|_{\Gamma_{b, i}}=0,(3 \mathrm{a}-\mathrm{b})
\end{array}
$$

where $\boldsymbol{n}$ is the unit normal exterior to $\Omega_{i}, \boldsymbol{h}_{i}$ is the magnetic field, $\boldsymbol{b}_{i}$ is the magnetic flux density, $\boldsymbol{e}_{i}$ is the electric field, $\boldsymbol{j}_{i}$ current density, $\mu_{i}$ is the magnetic permeability and $\sigma_{i}$ is the electric conductivity.

The fields $\boldsymbol{h}_{s, i}$ and $\boldsymbol{j}_{s, i}$ in (2a-b) are VSs expressed as changes of permeability and $\boldsymbol{j}_{s, i}$ for changes of conductivity. In the frame of the SPM, for changes in a region, from $\mu_{f}$ and $\sigma_{f}$ for problem $(i=f)$ to $\mu_{k}$ and $\sigma_{k}$ for problem $(i=k)$, the associated VSs $\boldsymbol{b}_{s, i}$ and $\boldsymbol{j}_{s, i}$ are [1].

$$
\begin{aligned}
\boldsymbol{h}_{s, k} & =\left(\mu_{k}^{-1}-\mu_{f}^{-1}\right) \boldsymbol{b}_{f}, \\
\boldsymbol{j}_{s, k} & =\left(\sigma_{k}-\sigma_{f}\right) \boldsymbol{e}_{f},
\end{aligned}
$$

for the total fields to be related by $\boldsymbol{h}_{f}+\boldsymbol{h}_{k}=$ $\left(\mu_{k}^{-1}\left(\boldsymbol{b}_{f}+\boldsymbol{b}_{k}\right)\right.$ and $\boldsymbol{j}_{f}+\boldsymbol{j}_{k}=\sigma_{k}\left(\boldsymbol{e}_{f}+\boldsymbol{e}_{k}\right)$.

\subsection{Weak formulation for magnetic vector potential}

By starting from the Ampere's law in (1a), the weak form of a magnetic vector potential of SP $i(i=f, k \ldots)$ is written as [1], [7],

$$
\left(\mu_{i}^{-1} \boldsymbol{b}_{i}, \operatorname{curl} \boldsymbol{a}_{i}^{\prime}\right)_{\Omega_{i}}+\left(\boldsymbol{h}_{s, i}, \operatorname{curl} \boldsymbol{a}_{i}^{\prime}\right)_{\Omega_{i}}
$$




$$
\begin{gathered}
-\left(\sigma_{i} \boldsymbol{e}_{i}, \boldsymbol{a}_{i}^{\prime}\right)_{\Omega_{c, i}}+<\boldsymbol{n} \times \boldsymbol{h}_{i}, \boldsymbol{a}_{i}^{\prime}>_{\Gamma_{h, i}} \\
=\left(\boldsymbol{j}_{s}, \boldsymbol{a}_{i}^{\prime}\right)_{\Omega_{s, i}} \forall \boldsymbol{a}_{i}^{\prime} \in \boldsymbol{H}_{i}^{1}\left(\operatorname{Curl}, \Omega_{i}\right) .
\end{gathered}
$$

Let us now introduce the magnetic vector potential and the electric field $\boldsymbol{e}_{i}$, that is

$$
\operatorname{curl} \boldsymbol{a}_{i}=\boldsymbol{b}_{i}, \boldsymbol{e}_{i}=-\boldsymbol{\partial}_{t} \boldsymbol{a}_{i}-\operatorname{grad} v_{i},(7 \mathrm{a}-\mathrm{b})
$$

where $v_{i}$ is the electric scalar potential defined in the conducting region $\Omega_{c, i}$.

By substituting the equations (7a-b) into the equation (6), we get

$$
\begin{gathered}
\left(\mu_{i}^{-1} \operatorname{curl} \boldsymbol{a}_{i}, \operatorname{curl} \boldsymbol{a}_{i}^{\prime}\right)_{\Omega_{i}}+\left(\boldsymbol{h}_{s, i}, \operatorname{curl} \boldsymbol{a}_{i}^{\prime}\right)_{\Omega_{i}} \\
+\left(\sigma_{i} \partial_{t} \boldsymbol{a}_{i}, \boldsymbol{a}_{i}^{\prime}\right)_{\Omega_{c, i}}+\left(\sigma_{i} \operatorname{grad} v_{i}, \boldsymbol{a}_{i}^{\prime}\right)_{\Omega_{c, i}} \\
+<\boldsymbol{n} \times \boldsymbol{h}_{i}, \boldsymbol{a}_{i}^{\prime}>_{\Gamma_{h, i}} \\
=\left(\boldsymbol{j}_{s}, \boldsymbol{a}_{i}^{\prime}\right)_{\Omega_{s, i}}, \forall \boldsymbol{a}_{i}^{\prime} \in \boldsymbol{H}_{i}^{1}\left(\operatorname{Curl}, \Omega_{i}\right),
\end{gathered}
$$

where $\boldsymbol{H}_{i}^{1}\left(\mathrm{Curl}, \Omega_{i}\right)$ is a fuction space defined on $\Omega_{i}$ containing the basis functions for $\boldsymbol{a}_{i}$ as well as for the test function $\boldsymbol{a}_{i}^{\prime}$ (at the discrete level, this space is defined by edge FEs; the gauge is based on the tree-co-tree technique $[1]) ;(., .)_{\Omega_{i}}$ and $<_{., .}>_{\Gamma_{h, i}}$ respectively denote a volume integral in $\Omega_{i}$ and a surface integral on $\Gamma_{h, i}$ of the product of their vector field arguments.

The tangential component of $\boldsymbol{h}_{i} \quad\left(\boldsymbol{n} \times \boldsymbol{h}_{i}\right)$ in (8) is considered as a homogeneous Neumann BC on the boundary $\Gamma_{h, i}$ of $\Omega_{i}$ given in (3a), imposing a symmetry condition of "zero crossing current", i.e.

$$
\begin{aligned}
\boldsymbol{n} \times\left.\boldsymbol{h}_{i}\right|_{\Gamma_{h}}=0 & \left.\Rightarrow \boldsymbol{n} \cdot \boldsymbol{h}_{i}\right|_{\Gamma_{h}}=\left.0 \Leftrightarrow \boldsymbol{n} \cdot \boldsymbol{j}_{i}\right|_{\Gamma_{h}} \\
& =0 .
\end{aligned}
$$

Weak formulation for subproblem $\left(\mathrm{SP}_{f}\right)$

Based on the general equation presented in (8), the weak formulation for the stranded inductors $\left(\mathrm{SP}_{f}\right)$ is written as

$$
\left(\mu_{f}^{-1} \operatorname{curl} \boldsymbol{a}_{f}, \operatorname{curl} \boldsymbol{a}_{f}^{\prime}\right)_{\Omega_{f}}+<\boldsymbol{n} \times \boldsymbol{h}_{f}, \boldsymbol{a}_{f}^{\prime}>_{\Gamma_{h, f}}
$$$$
=
$$

$\left(\boldsymbol{j}_{s}, \boldsymbol{a}_{f}^{\prime}\right)_{\Omega_{s, f}}, \forall \boldsymbol{a}_{f}^{\prime} \in \boldsymbol{H}_{f}^{1}\left(\operatorname{Curl}, \Omega_{f}\right)$, where $\boldsymbol{j}_{S}$ is the fixed electric current density in the inductors. The surface integral term on $\Gamma_{h, f}$ in (10) is given as a natural BC of type (2 a), usually zero.

Weak formulation for volume correction subproblem $\left(\mathrm{SP}_{k}\right)$

The solution obtained from $\mathrm{SP}_{f}$ in (11) is now considered as VSs for a current $\mathrm{SP}_{k}$ via a projection method [1], [7]. Thus, the weak form for $\mathrm{SP}_{k}$ is expressed through (8), i.e.

$$
\begin{gathered}
\left(\mu_{k}^{-1} \operatorname{curl} \boldsymbol{a}_{k}, \operatorname{curl} \boldsymbol{a}_{k}^{\prime}\right)_{\Omega_{k}}+\left(\boldsymbol{j}_{s, k}, \boldsymbol{a}_{k}^{\prime}\right)_{\Omega_{k}} \\
+\left(\boldsymbol{h}_{s, k}, \operatorname{curl} \boldsymbol{a}_{k}^{\prime}\right)_{\Omega_{k}}+\left(\sigma_{k} \partial_{t} \boldsymbol{a}_{k}, \boldsymbol{a}_{k}^{\prime}\right)_{\Omega_{c, k}} \\
+\left(\sigma_{k} \operatorname{grad} v_{k}, \boldsymbol{a}_{k}^{\prime}\right)_{\Omega_{c, k}}=0 \\
\forall \boldsymbol{a}_{k}^{\prime} \in \boldsymbol{H}_{k}^{1}\left(\operatorname{Curl}, \Omega_{k}\right),
\end{gathered}
$$

where VSs $\boldsymbol{h}_{s, k}$ and $\boldsymbol{j}_{s, k}$ are given in (4) and (5). For that, the equation (11) becomes

$$
\begin{gathered}
\left(\mu_{k}^{-1} \operatorname{curl} \boldsymbol{a}_{k}, \operatorname{curl} \boldsymbol{a}_{k}^{\prime}\right)_{\Omega_{k}}+ \\
\left(\left(\mu_{k}^{-1}-\mu_{f}^{-1}\right) \operatorname{curl} \boldsymbol{a}_{f}, \operatorname{curl} \boldsymbol{a}_{k}^{\prime}\right)_{\Omega_{k}} \\
+\left(\left(\sigma_{k}-\sigma_{f}\right) \operatorname{grad} v_{f}, \boldsymbol{a}_{k}^{\prime}\right)_{\Omega_{k}}+ \\
\left(\sigma_{k} \partial_{t} \boldsymbol{a}_{k}, \boldsymbol{a}_{k}^{\prime}\right)_{\Omega_{c, k}}+\left(\sigma_{k} \operatorname{grad} v_{k}, \boldsymbol{a}_{k}^{\prime}\right)_{\Omega_{c, k}}=0 \\
\forall \boldsymbol{a}_{k}^{\prime} \in \boldsymbol{H}_{k}^{1}\left(\operatorname{Curl}, \Omega_{k}\right) .
\end{gathered}
$$

At the discrete level, the source quantity $\boldsymbol{a}_{f}$, initially in mesh of $\mathrm{SP}_{f}$ has to be projected in mesh of $\mathrm{SP}_{k}$ via a projection method, i.e

$$
\begin{gathered}
\left(\operatorname{curl} \boldsymbol{a}_{f-k}, \operatorname{curl} \boldsymbol{a}_{k}^{\prime}\right)_{\Omega_{k}}=\left(\operatorname{curl} \boldsymbol{a}_{f}, \operatorname{curl} \boldsymbol{a}_{k}^{\prime}\right)_{\Omega_{k}}, \\
\forall \boldsymbol{a}_{k}^{\prime} \in \boldsymbol{H}_{k}^{1}\left(\operatorname{Curl}, \Omega_{k}\right),
\end{gathered}
$$

where $\boldsymbol{H}_{k}^{1}\left(\mathrm{Curl}, \Omega_{k}\right)$ is a gauged curl-conform function space for the $k$-projected source $\boldsymbol{a}_{f-k}$ (the projection of $\boldsymbol{a}_{f}$ on mesh $\mathrm{SP}_{k}$ ) and the test function $\boldsymbol{a}_{k}^{\prime}$.

The final solution is then superposition of SP solutions obtained in (10) and (12), i.e.

$$
\boldsymbol{a}_{\text {total }}=\boldsymbol{a}_{f}+\boldsymbol{a}_{k},
$$

$\boldsymbol{b}_{\text {total }}=\operatorname{curl} \boldsymbol{a}_{\text {total }}$

$$
=\operatorname{curl} \boldsymbol{a}_{f}+\operatorname{curl} \boldsymbol{a}_{k} \text {. }
$$


The EMF $\boldsymbol{F}_{\text {total }}$ is now obtained via the cross product of the leakage magnetic flux in the air gap (between the core and coils) and the electric current density. This can be done by the post-processing, i.e.,

$$
\boldsymbol{F}_{\text {total }}=\int\left(\operatorname{curl} \boldsymbol{a}_{f}+\operatorname{curl} \boldsymbol{a}_{k}\right) \times \boldsymbol{j} d \Omega_{\text {air }}
$$

\section{Application test}

The test problem is a practical problem consisting of two inductors and a core depicted in Figure 2, with $f=50 \mathrm{~Hz}, \mu_{r, \text { core }}=$ $100, \sigma_{\text {core }}=6.484 \frac{\mathrm{MS}}{\mathrm{m}}$.

Flux lines with a real part of magnetic vector potential $\left(\boldsymbol{a}_{\text {total }}\right)$ due to the imposed electric currents flowing in stranded inductors is pointed out in Figure 3. The distribution of magnetic flux density is then obtained by taking curl of $\boldsymbol{a}_{\text {total }}$, i.e. $\boldsymbol{b}_{\text {total }}=$ curl $\boldsymbol{a}_{\text {total }}$ pointed out in Figure 4.

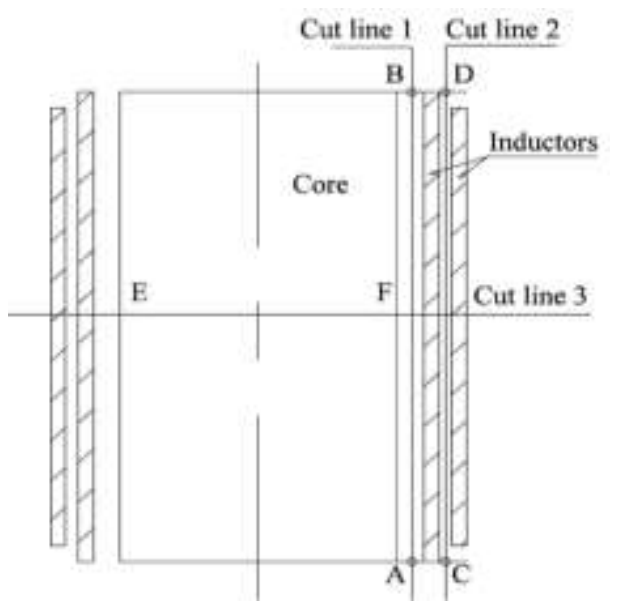

Figure 2. 2-D geometry of a core and two inducotrs
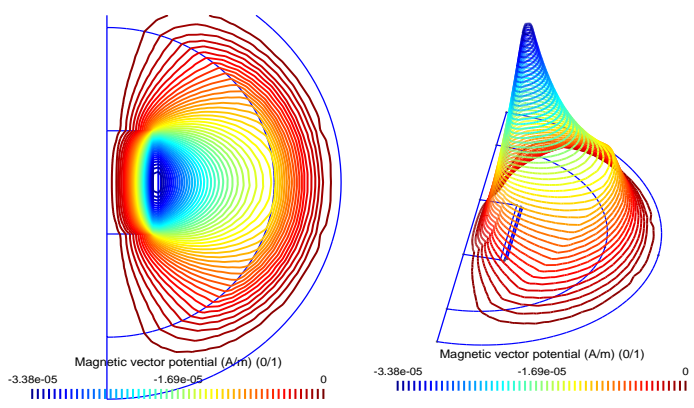

Figure 3. Flux lines with a real part on magnetic vector potential $\left(\boldsymbol{a}_{\text {total }}=\boldsymbol{a}_{f}+\boldsymbol{a}_{k}\right)$.

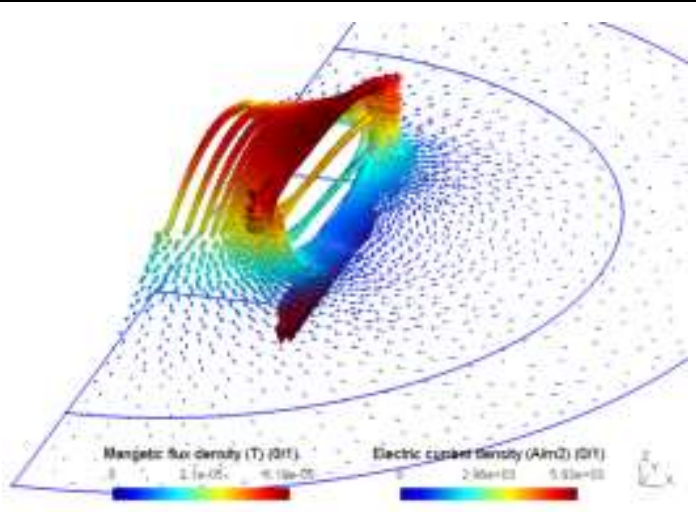

Figure 4. Distribution of magnetic flux density

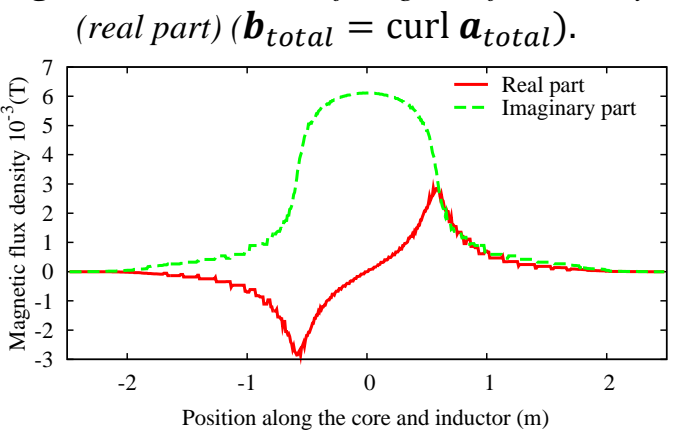

Figure 5. The cut lines of magnetic flux density along the core and windings (inductors)

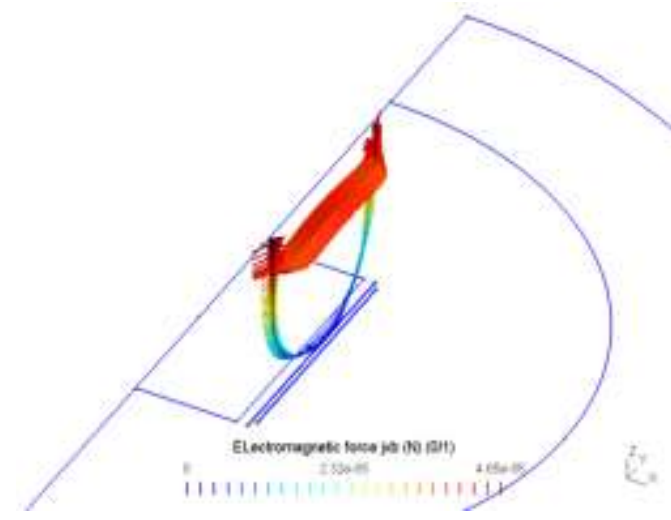

Figure 6. Distribution of electromagnetic force (real part) $\left(\boldsymbol{b}_{\text {total_leakage }} \times \boldsymbol{j}\right)$.

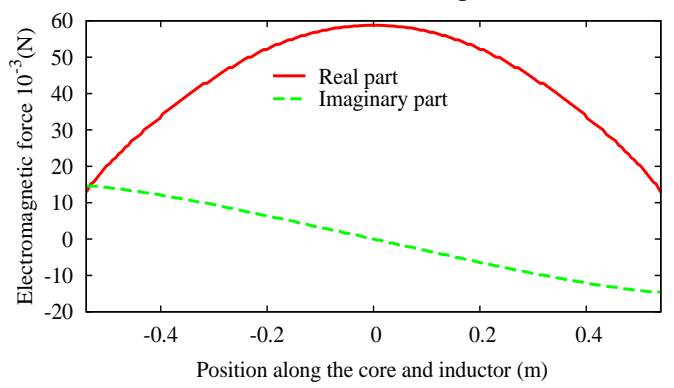

Figure 7. The cut lines of electromagnetic force at the air gap between the core and inductors. 


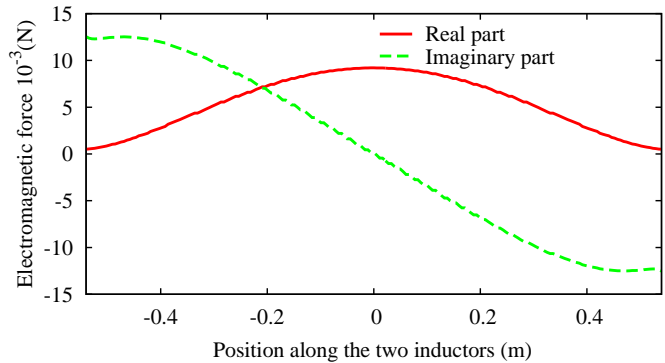

Figure 8. The cut lines of electromagnetic force at the air gap between two inductors

The cut lines of real and imaginary parts of magnetic flux density perpendicular the core and windings (as the cut line 3 in Fig. 2) is presented in Figure 5. For the real part, the field value is symmetrically distributed in the core, whereas, for the imaginary part, the field value at the middle of the core is higher than the regions near the bottom and top of the core.

The map of EMF is shown in Figure 6. The EMF on the real and imaginary parts with the cut line 1 between the core and inductors is pointed in Figure 7. The value is maximum at the middle of the inductors and reduces towards both sides of inductors for the real part, and slope from the head-to-end of inductors for the imaginary part.

The EMF on the real and imaginary parts with the cut line 2 (indicated in Fig. 2) between two inductors is shown in Figure 8. For this case, the value of EMF is lower than the case presented in Figure 7. This means that the distributions of the magnetic flux densitiy at the air gap is greater than that appearing between inductors.

\section{Conclusions}

All the steps of the SPM have been successfully with the magnetic vector potential formulation. This test practical problem has been applied to modelize the distributions of the EMF due to the leakage flux densities and the electric current densities. The obtained results can be also shown that there is a very good agreement of the method to help manufacturers and researchers to get ideas for creating productions in practice.

The source-codes of the SPM have been developed by author and two full professors (Prof. Patrick Dular and Christophe Geuzaine, University of Liege, Belgium). The achieved results of this paper have been simulated via Gmsh và GetDP (http://ace.montefiore.ulg.ac.be) proposed by Prof. Christophe Geuzaine and Prof. Patrick Dular. These are open-source codes for any one to be able to write sourcecodes according to the studied problems.

\section{REFERENCES}

[1]. V. Q. Dang, P. Dular, R. V. Sabariego, L. Krähenbühl, and C. Geuzaine, "Subproblem approach for Thin Shell Dual Finite Element Formulations," IEEE Trans. Magn., vol. 48, no. 2, pp. 407-410, 2012.

[2]. S. Koruglu, P. Sergeant, R. V. Sabarieqo, V. Q. Dang, and M. De Wulf, "Influence of contact resistance on shielding efficiency of shielding gutters for high-voltage cables," IET Electric Power Applications, vol. 5, no. 9, pp. 715-720, 2011.

[3]. J. S. Kim, "Electromagnetic Force Calculation Method in Finite Element Analysis for Programmers," Univeral Journal of Electrical and Electronic Engineering, vol. 6, no. 3A, pp. 62-67, 2019.

[4]. A. Bermúdez, A. L. Rodríguez, and I. Villar, "Extended formulas to compute resultant and contact electromagnetic force and torque from Maxwell stress tensors," IEEE Trans. Magn., vol. 53, no. 4, pp. 1-9, 2017.

[5]. H. M. Ahn, J. Y. Lee, J. K. Kim, Y. H. Oh, S. Y. Jung, and S. C. Hahn, "Finite-Element Analysis of Short-Circuit Electromagnetic Force in Power Transformer," Industry Applications IEEE Transactions on, vol. 47, no. 3, pp. 1267-1272, 2011.

[6]. Y. Hou et al., "Analysis of back electromotive force in RCEML," 2014 17th International Symposium on Electromagnetic Launch Technology, La Jolla, CA, 2014, pp. 1-6.

[7]. P. Dular, V. Q. Dang, R. V. Sabariego, L. Krähenbühl and C. Geuzaine, "Correction of thin shell finite element magnetic models via a subproblem method," IEEE Trans. Magn., vol. 47, no. 5, pp. 1158-1161, 2011. 